\title{
Agency in Transport Service: Implications of Traveller Mode Choice Objective and Latent Attributes Using Ransom Parameter Logit Model
}

\author{
A.M. Anwar ${ }^{\mathrm{a}^{*}}$ \\ K. Tieu ${ }^{\mathrm{a}}$ \\ P. Gibson ${ }^{\mathrm{a}}$ \\ K.T. Win ${ }^{\mathrm{a}}$ \\ M.J. Berryman ${ }^{\mathrm{b}}$
}

\begin{abstract}
This paper explains how principal-agent theory (PAT) can be used as an analytical tool to understand the traveller-Transport for NSW (TfNSW) relationship and minimise the agency problem in the relationship by examining traveller preferences for mode choices. The paper emphasises latent variables (LVs) and traditional objective attributes (TOAs) together during the choice process within the agency relationship, as a method by which the utility of the principal (traveller) can be maximised and evaluated using a discrete choice experiment, i.e. random parameter logit (RPL) model. The probability of car use is significantly higher than public transport, which indicates that an agency problem exists in the relationship and incorporating traveller preferences in the transport projects may minimise this problem.
\end{abstract}

Key words:PAT; Traveler; TfNSW; LVs; TOAs; RPL Model; Mode Choice.

\section{Principal-Agent Theory and Agency Problem}

PAT mainly focuses on the agency relationship between two parties. A relationship between two parties is understood when they involve in an association wherein one party (the principal) entrusts task and/or work to another party called agent to act on its behalf ${ }^{1,2}$. The important assumptions underlying PAT are that:

- $\quad$ Potential goal conflicts exist between principal(s) and agent(s);

- $\quad$ Each party acts in its own self-interest;

- Informational asymmetry frequently exists between principals and agents; and

- $\quad$ Agents are more risk averse than the principal.

Informational asymmetries and goal conflicts constitute the agency problem. This problem is appeared while the agent behaves opportunistically in such a way that works against the welfare

\footnotetext{
${ }^{\text {a }}$ Faculty of Engineering and Information Sciences, University of Wollongong NSW 2522, Australia.

${ }^{\mathrm{b}}$ SMART Infrastructure Facility, University of Wollongong NSW 2522, Australia.

*Corresponding author: Mehbub Anwar ahmma324@uowmail.edu.au.

http://dx.doi.org/10.14453/isngi2013.proc.54
} 
International Symposium for Next Generation Infrastructure October 1-4, 2013, Wollongong, Australia

of the principal ${ }^{3}$. The agency problem may arise in situations in which the principal cannot directly observe the agent's actions and when the self-interested agent pursues his private goals at the expense of the principal's goals ${ }^{4,5}$.

\section{Traveler and TfNSW Relationship}

Travellers have various kinds of preferences for their mode choice and the TfNSW has the capability to realise and address them. Due to experiences and skills of TfNSW, TfNSW is reasonably effective agent to fulfil the goals/expectations entrusted by travellers. The tax and travel fares paid by the citizens (travellers) are the source of funding of TfNSW, and travellers expect that TfNSW should perform on behalf of them. Therefore, the awareness about the traveler attributes, and maximisation of benefits has become the key issues in the discussion of the traveler-TfNSW relationship.

Provision of public transport (e.g. bus, train etc.) for travellers is one of the most important tasks of TfNSW who implements them with the help of transport operator. It is important to draw attention on the traveler choice attributes while providing services by TfNSW because TfNSW performs them at the traveler expenses. The public transport service should be as travellers demand to compete with their private car. Travellers are comfortable to use their own car and it makes complex situation in transport system for applying PAT. There is a conflict in choice and it is necessary to investigate the choice attributes towards the probability of mode use to find out the actual intention of travellers.

The role of TfNSW (agent) is to maximise the utility of the traveler (principal) within available resources. To realise the utility function of travellers to mode choice, TfNSW should have information about the nature of traveler's desires and demands. Thus, a metaphorical relationship is established in between traveler and TfNSW as indicated in PAT. In view of this relationship, the need to maximise travellers' utility is, therefore, important to examine travellers' preferences for various attributes of the modal choice. Travellers may not trust the quality of services performed by the TfNSW, because of its tendency to focus on its internal goals and opportunistic behaviour as opposed to more direct measures of the principals' goals.

To analyse the nature of traveller-TfNSW relationship, three hypotheses related to the travellers' (principals) preferences (both latent and observed) for modal choice attributes are generated and tested in this paper. Particularly, the relative importance of attributes related to traveller - TfNSW relationship, and how traveller preferences vary by socioeconomic and trip characteristics along with level of service and latent preferences, are examined by applying a series of RPL models.

\section{Hypotheses}

To understand the traveller-TfNSW relationship, three hypotheses have been identified from the travel behaviour literature ${ }^{6-15}$. They are:

Hypothesis 1 (H1): Traveller preferences influence TfNSW's decisions on modal services.

Hypothesis 2 (H2): Individual specific attributes affect TfNSW's planning of modal services. 
Hypothesis 3 (H3): Mode specific attributes and nature of trips have an effect also on TfNSW's decisions on modal service.

\section{Data}

The key data source of this study was cross-sectional 2008/09 household travel survey (HTS) data. This is the largest and most comprehensive household travel survey of Sydney conducted by the Bureau of Transport Statistics (BTS) of Transport Department, New South Wales (NSW). BTS conducted a household questionnaire survey in four areas: Sydney, Newcastle and Illawarra and collected four types of data: household data, person data, trip data and linked trip data. For this particular study, only 'Sydney' and 'person data' have been taken into consideration for data analysis. Data collected from 82121 trips were used in this analysis as a sample size.

Six LVs and thirteen objective attributes have been evaluated to determine the impact on travellers' mode choice with the adequacy of objective attributes reflecting LVs. Latent variables are: (i) comfort, (ii) convenience, (iii) safety, (iv) flexibility, (v) reliability, and (vi) satisfaction and twenty indicators described in Table 1 were set to explain them. The thirteen explanatory variables (TOAs) are under three categories:

1) Level of services (LOS): travel time (in minutes), travel cost (in Australian dollars), waiting time (in minutes);

2) Socio-economic characteristics (SEC): age (in years), personal annual income (in Australian dollar), family size, gender ( 1 if male, 0 otherwise), car ownership per adult, having children (0-14 years), and number of full time workers of household; and

3) Trip characteristics (TC): trip rate (trip per person per day), trip purpose ( 1 if work, 0 otherwise) and distance travelled (in kilometre).

The following is the list of psychometric indicators (Table 1) that were considered in the modelling approach of this study for structuring the influence of LVs in traveller preferences.

Table 1. Description of latent variables.

\begin{tabular}{|c|c|c|}
\hline $\begin{array}{l}\text { Latent } \\
\text { factors }\end{array}$ & Explained by (indicators) & Definitions \\
\hline \multirow[t]{3}{*}{ Comfort } & - Enjoy time to read/relax on vehicle & $\begin{array}{l}\text { Importance with } 1 \text {, otherwise } \\
0\end{array}$ \\
\hline & - Stressfulness on vehicle & $\begin{array}{l}\text { Importance with } 1 \text {, otherwise } \\
0\end{array}$ \\
\hline & - Service slower & Importance with 1 , otherwise \\
\hline \multirow[t]{3}{*}{ Convenience } & - Mode availability & Importance with 1 , otherwise \\
\hline & - Accessibility (does not go where required) & Importance with 1 , otherwise \\
\hline & - Timetable availability & $\begin{array}{l}\text { Importance with } 1 \text {, otherwise } \\
0\end{array}$ \\
\hline
\end{tabular}




\begin{tabular}{|c|c|c|}
\hline \multirow[t]{3}{*}{ Safety } & - Safety response for mode used in $1^{\text {st }}$ trip & $\begin{array}{l}\text { Importance with } 1 \text {, otherwise } \\
0\end{array}$ \\
\hline & - Safety response for mode used in $2^{\text {nd }}$ trip & $\begin{array}{l}\text { Importance with } 1 \text {, otherwise } \\
0\end{array}$ \\
\hline & - Safety response for mode used in $3^{\text {rd }}$ trip & $\begin{array}{l}\text { Importance with } 1 \text {, otherwise } \\
0\end{array}$ \\
\hline \multirow[t]{3}{*}{ Flexibility } & $\begin{array}{l}\text { - Fixed start and finish times - each day can } \\
\text { vary } \\
\text { - Rotating shift }\end{array}$ & $\begin{array}{l}\text { Importance with } 1 \text {, otherwise } \\
0 \\
\text { Importance with } 1 \text {, otherwise } \\
0\end{array}$ \\
\hline & - Roster shift & Importance with 1 , otherwise \\
\hline & - Variable hours & Importance with 1 , otherwise \\
\hline \multirow[t]{3}{*}{ Reliability } & - Frequency & Importance with 1 , otherwise \\
\hline & - Punctuality & Importance with 1 , otherwise \\
\hline & - Faster & $\begin{array}{l}\text { Importance with } 1 \text {, otherwise } \\
0\end{array}$ \\
\hline \multirow[t]{4}{*}{ Satisfaction } & - Cleanliness & Importance with 1 , otherwise \\
\hline & - Travel time & Travel time in minutes \\
\hline & - Travel cost & $\begin{array}{l}\text { Travel cost in Australian } \\
\text { dollar }\end{array}$ \\
\hline & - Waiting time & Waiting time in minutes \\
\hline
\end{tabular}

\section{Steps and methods of the study}

There are two approaches available for incorporating LVs into the choice models (i) sequential (also known as two-step) approach, where the LVs are needed to be constructed before being included into the discrete choice model as regular explanatory variables ${ }^{16,9}$, and (ii) the simultaneous approach, where both processes are done simultaneously,17. The two-step approach is performed to estimate the results in this paper. 
Determine relevant data (variables) (i) Latent variables; and (ii) traditional objective attributes (TOAs)

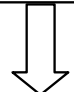

Source the data and get permission to use (Household travel survey data): Signing a contract with BTS (Bureau of Transport Statistics) of TfNSW to get access of the data

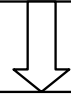

Data screening: Box plot (homoscedasticity and outliers), correlation matrix (multicollinearity) and Q-Q plot (normal distribution)

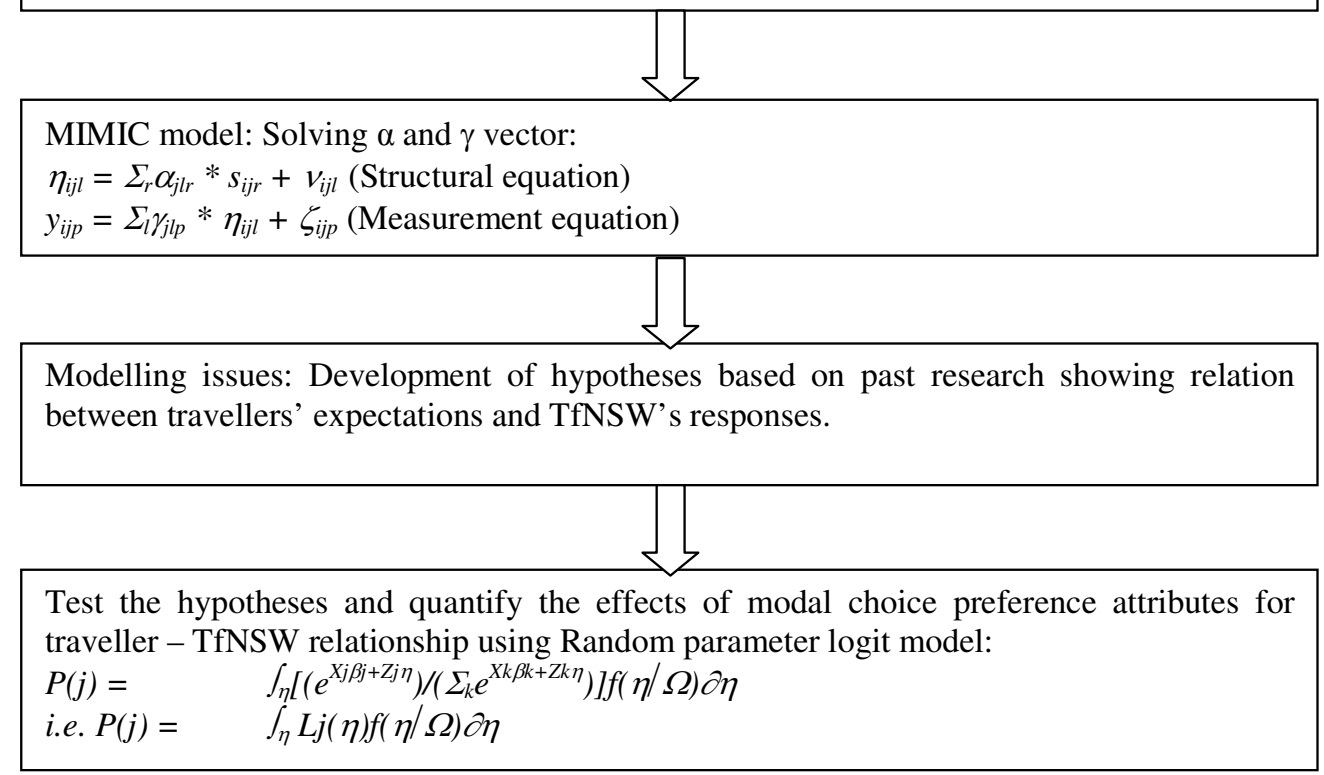

Figure 1. Workflow of this study.

Figure 1 shows the work flow/steps of this study and it clearly explains the evaluation steps of preference attributes both from traveller and transport mode perspective leading to the travellers' choice of a mode of transport. Travellers pay more importance for the preferable attributes for selecting the modal service and therefore, TfNSW should perform the entrusted services at reasonable manner as per travellers demand which forma a metaphorical relationship (contract) as indicated in PAT. In practice, different types of modes are available to travellers and they choose the mode considering the perceived service quality acted by the TfNSW. The nature of the traveller - TfNSW relationship within modal choice can also influence traveller satisfaction with the degree of better services provided by TfNSW. A MIMIC (multiple indicators and multiple causes) model is used to test the reliability of latent variable indicators and to solve the $\alpha$ and $\gamma$ vector matrix in structural and measurement equations respectively in Figure 1 . These vector matrixes are useful to quantify the effect of LVs and validate the indicators of LVs respectively. The information obtained from MIMIC mode has been used in a random parameter logit (RPL) model, which can overcome the problem of independence of irrelevant alternatives 
(IIA) and independent and identically distributed (IID) assumptions because of addition an additional random term in the function as stochastic component.

\section{Empirical Results}

Reliability of the indicators listed in Table 1 was tested using factor analytic models (exploratory and confirmatory factor model). The factor analytic model focuses solely on how, and the extent to which, the observed variables are linked to their underlying latent factors ${ }^{18}$. However, due to the limited space allocation for this paper, the outcomes of $\alpha$ vector matrix in structural equation and $\gamma$ vector matrix in measurement equation are not presented here. For further details, please see Anwar et al. ${ }^{19}$.

Table 2 discusses the results obtained from RPL models. The models were estimated in LIMDEP (Nlogit 4), econometric software, using maximum likelihood estimation procedures. A series of four RPL models were estimated with considering TOAs and LVs. Only LOS attributes are included in TRPL1. Then LOS and SEC are considered in TRPL2 model. In TRPL3 model, all TOAs have been incorporated simultaneously and finally, HRPL explains the impact of TOAs and LVs together.

Interestingly it is observed that significance level of RPL2 is stronger than RPL1 and RPL3 is stronger than RPL2. It indicates good explanatory power of the models while a number of relevant attributes is included in the model. Here, the model statistics indicate that the hybrid RPL model is the best model because LVs are integrated into the model, which provides valuable insights into the motivational processes to mode choice. Results confirm that travel time, waiting time, travel cost, and car ownership among TOAs, and safety and reliability among LVs are mostly leading and significant predictors of mode choice. Further understanding is that the desire for comfort and convenience positively impacts commuter mode choice. It is noted that due to the inclusion of LVs, the effects of TOAs are decreased substantially and in that sense delivered true additional insight. Considering LVs, it is observed that likelihood of train use has been increased though still car use as a driver is dominant. In contrast, as the probability of bus usage is declining, bus companies need to improve the services as traveller demands and thus the agency problem might be minimised. From the results, since the probability of car use is significantly high in comparison to public transport use, the agency problem persists in the traveller-TfNSW relationship. This study has shown then that the integration of LVs in transport mode related projects undertaken by TfNSW is imperative to resolve the agency problem.

Table 2. Results of random parameter logit models (t-values within the parenthesis).

\begin{tabular}{|l|l|l|l|l|}
\hline Attributes & TRPL $^{\mathbf{1}}$ & TRPL $^{\mathbf{2}}$ & TRPL $^{\mathbf{3}}$ & HRPL \\
\hline \multicolumn{5}{|l|}{} \\
\hline Random parameter in utility functions \\
Travel cost (mean) & $-3.14(-2.11)$ & $-3.19(-2.56)$ & $-3.20(-5.55)$ & $-2.11(-2.62)$ \\
Travel cost (st.dev.) & $1.07(1.99)$ & $1.02(2.45)$ & $1.05(3.45)$ & $1.06(4.21)$ \\
\hline Waiting time (mean) & $-1.72(-2.12)$ & $-1.85(-3.11)$ & $-1.93(-3.15)$ & $-1.75(-3.14)$ \\
Waiting time (st.dev.) & $0.08(3.11)$ & $0.03(3.41)$ & $0.004(2.48)$ & $0.004(2.99)$ \\
\hline Age (mean) & & $-0.22(-1.89)$ & $-0.11(-1.11)$ & $-0.09(-2.84)$ \\
Age (st.dev.) & & $0.48(1.66)$ & $0.22(2.01)$ & $0.58(2.63)$ \\
\hline Car ownership (mean) & $1.84(3.52)$ & $1.91(5.21)$ & $1.89(4.00)$ \\
Car ownership (st.dev.) & & $0.03(3.51)$ & $0.02(4.21)$ & $0.04(4.44)$ \\
\hline Having children (mean) & & $-1.78(-6.44)$ & $-1.80(-5.41)$ & $-1.77(-5.02)$ \\
\hline
\end{tabular}


International Symposium for Next Generation Infrastructure

October 1-4, 2013, Wollongong, Australia

\begin{tabular}{|c|c|c|c|c|}
\hline Attributes & TRPL $^{1}$ & TRPL $^{2}$ & TRPL $^{3}$ & HRPL \\
\hline Having child (st.dev.) & & $0.11(3.65)$ & $0.26(3.11)$ & $0.12(2.87)$ \\
\hline Trip purpose (mean) & & & $0.07(3.44)$ & $0.06(2.15)$ \\
\hline Trip purpose (st.dev.) & & & $0.003(2.33)$ & $0.001(3.63)$ \\
\hline $\begin{array}{l}\text { Comfort (mean) } \\
\text { Comfort (st.dev.) }\end{array}$ & & & & $\begin{array}{l}3.32(7.89) \\
0.12(5.66)\end{array}$ \\
\hline Convenience (mean) & & & & $3.18(4.66)$ \\
\hline $\begin{array}{l}\text { Convenience (st.dev.) } \\
\text { Safety (mean) }\end{array}$ & & & & $\frac{0.22(5.66)}{5.18(11.11)}$ \\
\hline Safety (st.dev.) & & & & $0.45(9.84)$ \\
\hline Flexibility (mean) & & & & $0.73(1.00)$ \\
\hline Flexibility (st.dev.) & & & & $0.30(2.16)$ \\
\hline Reliability (mean) & & & & $5.17(11.10)$ \\
\hline Reliability (st.dev.) & & & & $0.01(9.15)$ \\
\hline Satisfaction (mean) & & & & $1.23(2.66)$ \\
\hline Satisfaction (st.dev.) & & & & $0.09(2.99)$ \\
\hline \multicolumn{5}{|c|}{ Nonrandom parameter in utility functions } \\
\hline Age & $-0.08(-0.99)$ & & & \\
\hline Having children under 5 yrs & $-0.97(-3.62)$ & & & \\
\hline Car ownership & $1.27(3.91)$ & & & \\
\hline Trip purpose & $0.97(2.89)$ & $0.97(2.91)$ & & \\
\hline Travel time & $-1.17(-7.85)$ & $-1.17(-8.77)$ & $-1.19(-6.42)$ & $-1.11(-3.63)$ \\
\hline Gender & $0.29(1.89)$ & $0.32(2.13)$ & $0.39(2.15)$ & $0.21(2.69)$ \\
\hline Income & $1.32(1.85)$ & $1.69(1.11)$ & $1.98(1.91)$ & $1.50(0.89)$ \\
\hline Family size & $-0.94(-0.45)$ & $0.94(1.01)$ & $0.93(0.99)$ & $0.94(1.00)$ \\
\hline Full time workers of $\mathrm{HH}$ & $0.97(0.32)$ & $0.97(1.45)$ & $0.97(0.85)$ & $0.97(1.01)$ \\
\hline Trip rate & $0.91(1.11)$ & $0.91(1.00)$ & $0.91(1.74)$ & $0.91(1.86)$ \\
\hline Distance travelled & $-0.19(-1.89)$ & $-0.17(-1.11)$ & $-0.78(-1.01)$ & $-0.24(-1.12)$ \\
\hline \multicolumn{5}{|l|}{ Mode constant } \\
\hline Car as a passenger (base) & 0 & 0 & 0 & 0 \\
\hline Car as a driver & $-2.22(-2.45)$ & $-2.23(-2.54)$ & $-2.22(-3.10)$ & $-2.41(-9.00)$ \\
\hline Train & $-1.00(-1.99)$ & $-1.17(-1.98)$ & $-2.18(-3.41)$ & $-2.39(-7.15)$ \\
\hline Bus & $-0.11(-0.52)$ & $-0.12(-1.23)$ & $-0.14(-1.22)$ & $-0.10(-1.53)$ \\
\hline \multicolumn{5}{|l|}{ Heterogeneity around the mean } \\
\hline Travel cost :Income & $-0.11(-4.21)$ & $-0.10(-2.98)$ & $-0.12(-3.62)$ & $-0.01(-3.99)$ \\
\hline Waiting time :Income & $-0.54(-3.56)$ & $-0.54(-2.56)$ & $-0.54(-2.96)$ & $-0.03(-3.85)$ \\
\hline Age: Income & & $-0.11(-1.89)$ & $-0.08(-1.98)$ & $-0.12(-2.14)$ \\
\hline Car ownership: Income & & $0.02(3.12)$ & $0.01(3.01)$ & $0.65(5.14)$ \\
\hline Having child: income & & $-0.02(-1.99)$ & $-0.09(-2.66)$ & $-0.17(-3.01)$ \\
\hline Purpose: Income & & & $0.01(4.01)$ & $0.05(3.01)$ \\
\hline Comfort: Income & & & & $0.09(3.10)$ \\
\hline Convenience: Income & & & & $0.10(2.89)$ \\
\hline Safety: Income & & & & $0.45(11.52)$ \\
\hline Flexibility: Income & & & & $0.05(2.45)$ \\
\hline Reliability: Income & & & & $0.31(10.20)$ \\
\hline Satisfaction: Income & & & & $0.08(5.10)$ \\
\hline \multicolumn{5}{|l|}{ Model statistics } \\
\hline Log likelihood function & -812.41 & -768.31 & -715.28 & -613.37 \\
\hline McFadden Pseudo R-squared & 0.21 & 0.25 & 0.27 & 0.36 \\
\hline Akaike Information Criterion (AIC) & 0.019 & 0.018 & 0.017 & 0.014 \\
\hline \multicolumn{5}{|l|}{ Modal choice probability } \\
\hline Car as a driver & 0.713 & 0.721 & 0.731 & 0.785 \\
\hline Car as a passenger & 0.080 & 0.075 & 0.055 & 0.010 \\
\hline Train & 0.159 & 0.160 & 0.181 & 0.190 \\
\hline
\end{tabular}




\begin{tabular}{|c|l|l|l|l|}
\hline Attributes & TRPL $^{\mathbf{1}}$ & TRPL $^{\mathbf{2}}$ & TRPL $^{\mathbf{3}}$ & HRPL \\
\hline Bus & 0.048 & 0.044 & 0.033 & 0.015 \\
\hline
\end{tabular}

Legend:

Significant at $90 \%$ level of confidence if $1.960>t \geq 1.645$;

Significant at $95 \%$ level of confidence if $2.576>t \geq 1.960$;

Significant at $99 \%$ level of confidence if $2.810>t \geq 2.576$

Significant at $99.5 \%$ level of confidence if $3.290>t \geq 2.810$;

Significant at $99.9 \%$ level of confidence if $t \geq 3.290$.

\section{Discussions and Conclusions}

The HRPL mode is more powerful than the TRPL model. It indicates that the LVs dominate the traveller choice process and TfNSW should aware about the travellers' dominating behavioural nature otherwise agency problem will continue. Therefore, the analysis of the traveller-TfNSW relationship is also relevant in the context of transport policy responses.

As a response to the agency problem (lack of awareness about travellers' utility functions) caused by goal conflicts in the traveller-TfNSW relationship, the policy response suggested that awareness about travellers' expectations should be concerned and addressed by TfNSW. Transport planners realise the importance of TfNSW measuring travellers' latent preferences in modal services, however little attention has been paid to the nature of such a policy response. This study has partly clarified the nature of such a policy response by indicating which attributes of the traveller-TfNSW relationship are most important to travellers.

With the analysis of exploring this relationship, it is understood that traveller's preference to mode choice is a fundamental factor and it supports TfNSW for the provision of effective and successful services. It seems that the process of response acted by TfNSW towards travellers' desires is highly complex. This paper simplifies the response mechanism so that the transport policy makers can incorporate the findings of this study into the future project. On the other way, to ration limited resource of TfNSW effectively, TfNSW needs to be aware of those attributes of travellers' choice process that should increase travellers' utility the most. Thus, the maximisation of traveller's utility helps to rectify the agency problem.

\section{References}

${ }^{1}$ Eisenhardt, K.M., "Agency theory: An assessment and review," Academy of Management Review, Vol. 14, No. 1, 1989, pp. 57-74.

${ }^{2}$ Rungtusanatham, M., Rabinovich, E., Ashenbaum, B. and Wallin, C., "Vendor-owned inventory management arrangements in retail: an agency theory perspective," Journal of Business Logistics, Vol. 28, No. 1, 2007, pp. 111-35. http://dx.doi.org/10.1002/j.2158-1592.2007.tb00234.x

${ }^{3}$ Barney, J.B., and Hesterly, W., "Organizational economics: Understanding the relationship between organizations and economic analysis," In handbook of organization, C. Stewart, H. Cynthia, and N. Walter R. (Eds.), London and Thousand Oaks: Sage Publications, 1996.

\footnotetext{
${ }^{4}$ Barney, J., and Ouchi, W. (eds.), Organizational economics, Jossey-Bass: San Francisco, 1986.
} 
International Symposium for Next Generation Infrastructure October 1-4, 2013, Wollongong, Australia

${ }^{5}$ Milgrom, P.R., and Roberts, J., Economics, organizations and management. Prentice-Hall: USA, 1992

${ }^{6}$ McFadden D., "The choice theory approach to marketing research. Marketing Science," Vol. 5, No. 4, 1986, pp. 275 - 297. http://dx.doi.org/10.1287/mksc.5.4.275

${ }^{7}$ Ashok, K., William, R.D., and Yuan, S., "Extending discrete choice models to incorporate attitudinal and other latent variables," Journal of Marketing Research, Vol. 39, No. 1, 2002, pp. 31-46. http://dx.doi.org/10.1509/jmkr.39.1.31.18937

${ }^{8}$ Morikawa T., Ben-Akiva M., and McFadden D. L., "Discrete choice models incorporating revealed preferences and psychometric data," Econometric Models in Marketing, Vol. 16, 2002, pp. 29-55.

${ }^{9}$ Johansson M.V, Heldt, T., and Johansson, P., "The effects of attitudes and personality traits on mode choice," Transportation Research Part A: Policy and Practice, Vol. 40, No. 6, 2006, pp. 507-525. http://dx.doi.org/10.1016/j.tra.2005.09.001

${ }^{10}$ Choo S., and Mokhtarian P.L., "What types of vehicle do people drive? The role of attitude and lifestyle in influencing vehicle type choice," Transportation Research Part A: Policy and Practice, Vol. 38, No. 3, 2004, pp. 201 - 222. http://dx.doi.org/10.1016/j.tra.2003.10.005

${ }^{11}$ Walker J., and Li, J., "Latent lifestyle preferences and household location decisions," Journal of Geographical Systems, Vol. 9, No. 1, 2007, pp. 77 - 101. http://dx.doi.org/10.1007/s10109-006-0030-0

${ }^{12}$ Ben-Akiva, M.E., Walker, J.L., Bernardino, A.T., Gopinath, D.A., Morikawa, T. and Polydoropoulou, A. "Integration of choice and latent variable models," In: Mahmassani, H.S. (ed.), Perpetual Motion: Travel Behaviour Research Opportunities and Challenges, Pergamon: Amsterdam, 2002.

${ }^{13}$ Ben-Akiva, M., Bradley, M., Morikawa, T., Benjamin, J., Novak, T., Oppewal, H., and Rao, V., "Combining revealed and stated preferences data", Marketing Letters, Vol. 5, No. 4, 1994, pp. 335-350. http://dx.doi.org/10.1007/BF00999209

${ }^{14}$ Ory, D., and Mokhtarian, P.L., "Modelling the structural relationships among short distance travel amounts, perceptions, affections and desires," Transportation Research Part A: Policy and Practice, Vol. 43, No. 1, 2009, pp. 26-43. http://dx.doi.org/10.1016/j.tra.2008.06.004

${ }^{15}$ Temme, D., Paulssen, M., and Dannewald, T., "Incorporating latent variables into discrete choice models - a simultaneous estimation approach using SEM software," BuR Business Research Journal, Vol. 1, No. 2, 2008, pp. 220-237. http://dx.doi.org/10.1007/BF03343535

${ }^{16}$ Yanez M.F., Raveau, S., and Ortuzar J. de D., "Inclusion of latent variables in Mixed Logit models: Modelling and forecasting," Transportation Research Part A: Policy and Practice, Vol. 44, No. 9, 2010, pp. 744-753. http://dx.doi.org/10.1016/j.tra.2010.07.007

${ }^{17}$ Bolduc, D., Boucher, N., and Alvarez-Daziano, R., "Hybrid choice modelling of new technologies for car choice in Canada," Transportation Research Record, Vol. 2082, 2008, pp. 63-71. http://dx.doi.org/10.3141/2082-08

${ }^{18}$ Byrne, B.M. Structural Equation Modeling with AMOS: Basic Concepts, Applications, and Programming, 2nd edition. Routledge, 2010.

${ }^{19}$ Anwar, A.H.M.M., Tieu, K., Gibson, P., Berryman, M., and Win, K.T., "Structuring the influence of latent variables in traveller preference heterogeneity," Proceedings of the 16th International Conference of Hong Kong Society for Transportation Studies, Hong Kong, pp. 141-148, 2011. 